\title{
Problem solving therapy improved quality of life and reduced pyschological distress in adults with cancer
}

Nezu AM, Nezu CM, Felgoise SH, et al. Project Genesis: assessing the efficacy of problem-solving therapy for distressed adult cancer patients. J Consult Clin Psychol 2003;71:1036-48.

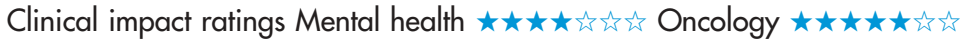

In patients 18-65 years of age with cancer and psychological distress, is problem solving therapy (PST) effective for improving quality of life and reducing measures of pyschological stress.

\section{METHODS}

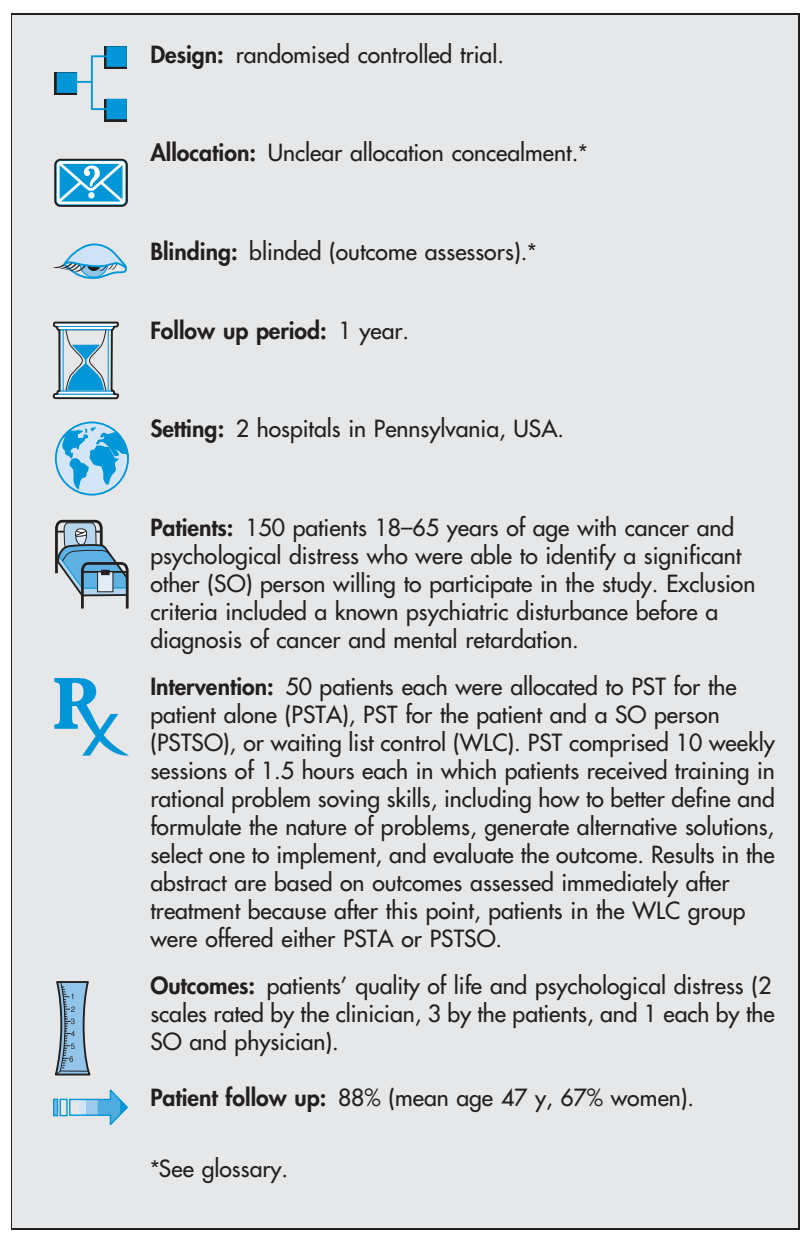

\section{MAIN RESULTS}

Improvement in overall quality of life and decrease in global psychological distress were greater in both the PSTA and PSTSO groups than in the WLC group ( $\mathrm{p}$ values $<0.01$ ). More patients in the PST groups than in the WLC group achieved a clinically significant decrease in psychological distress (table).

\section{CONCLUSION}

In patients $18-65$ years of age with cancer and psychological stress, problem solving therapy improved quality of life and reduced measures of pyschological distress.

For correspondence: $\mathrm{Dr}$ A M Nezu, Drexel University, Philadelphia, PA, USA. art.nezu@verizon.net

Source of funding: National Cancer Institute.
Probem solving therapy for patient alone (PSTA) or patient and significant other (PSTSO) $v$ waiting list (WL) in cancer with psychological distress*

\begin{tabular}{lllll}
\hline $\begin{array}{l}\text { Outcomes } \\
\text { immediately } \\
\text { after treatment }\end{array}$ & Comparison & Event rates & $\begin{array}{l}\text { RRR } \\
(95 \% \mathrm{Cl})\end{array}$ & $\begin{array}{l}\text { NNT } \\
(\mathrm{Cl}) \dagger\end{array}$ \\
\hline $\begin{array}{l}\text { No clinically } \\
\text { significant }\end{array}$ & PSTA $v \mathrm{WL}$ & $11 \% \vee 100 \%$ & $\begin{array}{l}89 \% \\
(76 \text { to } 95)\end{array}$ & $\begin{array}{l}2 \\
(2 \text { to } 2)\end{array}$ \\
$\begin{array}{l}\text { decrease in } \\
\begin{array}{l}\text { psychological } \\
\text { distress }\end{array}\end{array}$ & PSTSO $v \mathrm{WL}$ & $15 \% \vee 100 \%$ & $85 \%$ & 2 \\
$(71$ to 93) & $(2$ to 2)
\end{tabular}

*Abbreviations defined in glossary; event rates, RRR, NNT, and Cl calculated from data in article.

tThe point estimate $\mathrm{Cl}$ is a result of rounding.

\section{Commentary}

7

he study by Nezu et al is important because not only does it provide data that further supports the benefits of PST already reported in other clinical populations but also uses robust study methods to show the potential for a psychological intervention to improve the lives of those affected by cancer related distress. Although many published studies evaluating the effect of psychological interventions on morbidity associated with cancer exist, many are fraught with methodological flaws.' This high quality study constitutes a substantial improvement on many weaker studies in this area. Specific improvements include the fact that patients were followed up at 1 year and the use of inferential statistics, effect size, and ratings of clinical significance to examine the effect of the intervention. Outcome assessment using self report measures, clinician ratings, and ratings from an SO were included. The study also included measures to assess changes in problem solving, providing data suggesting that changes might be moderated by improvements in problem solving ability. Potential participants had to be able to name an SO, thus excluding people who may lack social support, a factor that is often associated with distress.

Although the benefits of supportive and psychological care interventions are well established, few patients with cancer receive these as part of routine care. ${ }^{2}$ The challenge now for those involved in the delivery of health care is how to ensure that patients access these interventions and that clinicians are properly trained to deliver psychological therapies such as PST to people with cancer who may benefit. Finally, it will be important to evaluate PST within a clinical effectiveness paradigm, chosen to reflect a wide range of clinical, sociodemographic, and psychological characteristics of patients.

Craig A White, ClinPsyD NHS Ayrshire and Arran \& University of Glasgow, Glasgow, UK

1 Newell SA, Sanson-Fisher RW, Savolainen NJ. Systematic review of psychological therapies for cancer patients: overview and recommendations for future research. J Natl Cancer Inst 2002;94:558-84.

2 Redman S, Turner J, Davis C. Improving supportive care for women with breast cancer in Australia: the challenge of modifying health systems. Psychooncology 2003;12:521-31. 